\title{
ORBITAL ENERGY CONTROL OF CYCLOADDITION REACTIVITY
}

\author{
REINER SUSTMANN
}

Organisch Chemisches Institut der Universitüt, 44 Münster, GFR

\begin{abstract}
A reactivity model for concerted cycloaddition reactions is presented which allows a systematization of substituent effects. The treatment is based on the frontier electron theory of Fukui. The consideration of the energy separations of HOMOs (Highest Occupied Molecular Orbitals) and LUMOs (Lowest Unoccupied Molecular Orbitals) leads to three reactivity types in these cycloadditions. For the Diels-Alder addition and 1,3-dipolar cycloadditions the occurrence of: 1. HOMO (Diene or Dipole) LUMO (olefin) controlled reactions, 2. HOMO (Diene or Dipole)-LUMO (olefin) and HOMO (olefin)LUMO (Diene or Dipole) controlled additions and 3. LUMO (Diene or Dipole)-HOMO (olefin) controlled cycloadditions is demonstrated. Each type exhibits a characteristic behaviour towards substituents in both reaction partners. A semiquantitative treatment of substituent effects together with an experimental verification is given.
\end{abstract}

\section{INTRODUCTION}

During the last two decades thermal cycloaddition reactions have been of interest to many chemists. The synthetic scope and the mechanistic implications both played an important part in the development $t^{1,2,3}$. The mechanisms by which cycloadducts are formed are still under investigation. Experimental criteria have been developed to test whether a cycloaddition takes place by a concerted formation of the new $\sigma$-bonds or whether an intermediate has to be invoked. These criteria are the stereospecificity in the formation of products, i.e. the retention of configuration of the reactants, the interception of intermediates, the correlation of structure and rate, and the dependence of reaction rates on solvent polarity.

The gathered experimental information received a theoretical foundation through the rules of conservation of orbital symmetry by Woodward and Hoffmann (W-H rules) ${ }^{4}$. Most of the experimental results are in accordance with this principle and many new experiments were stimulated. Another theoretical approach relates the mechanism with the occurrence of aromatic or antiaromatic transition states ${ }^{5}$. It leads essentially to the same conclusions. It is fallacious to think that there is no problem left as far as the mechanism is concerned. Is the retention of stereochemistry, the impossibility of intercepting intermediates or the independence of reaction rates from solvent polarity a sufficient proof for a concerted mechanism" This refers to the difficulty of defining an intermediate on a reaction coordinate. 
One can only state that on the basis of present experimental knowledge one cannot differentiate further. Another question : is it sufficient to test several examples of a certain type of reaction in order to postulate a common mechanism for all of these reactions? The question is connected with the dependence of a mechanism on the degree of substitution. As long as no further experimental tests have been devised, the conservation of orbital symmetry or the aromatic transition state theory seem to be well suited to rationalize the experimental facts.

There are, however, two more aspects of cycloaddition reactions. The influence of substituents on reaction rates and the problem of regioselectivity. Neither is dealt with by the $\mathrm{W}-\mathrm{H}$ rules. The influence of substituents on the rate of cycloadditions will be the present topic. Figure 1 shows the $(2+2)$

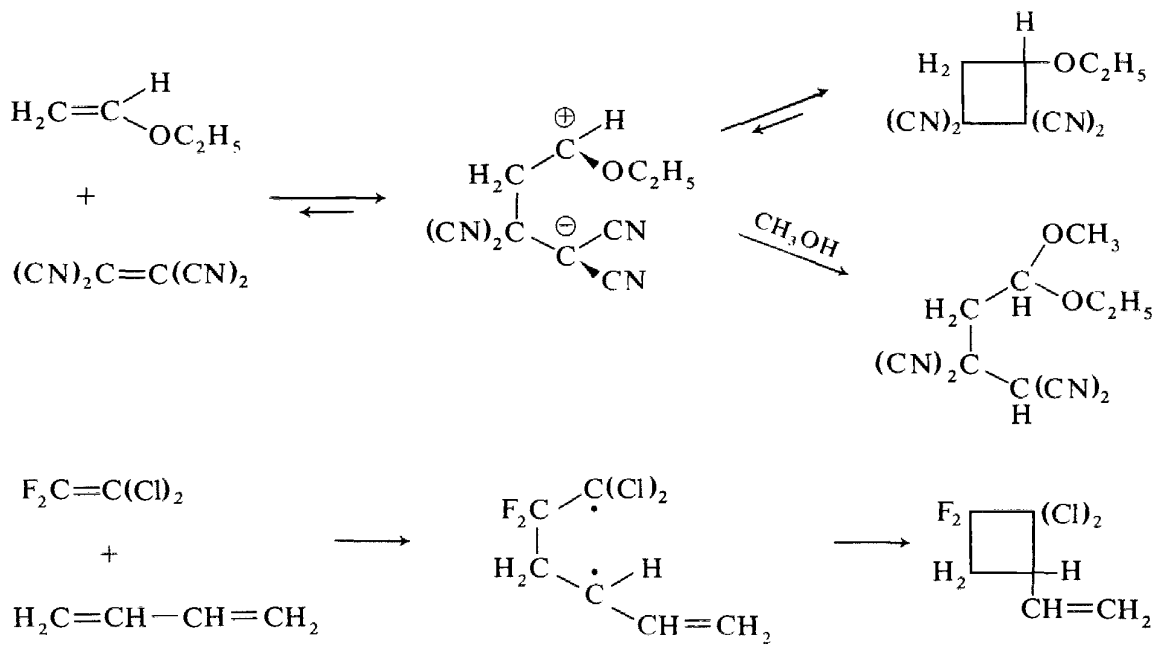

Figure 1. Ionic and biradical $\left({ }_{\pi}^{2}+{ }_{\pi} 2\right)$ cycloaddition [After (above) R. HUISGEN, R. SCHUG and G. STEINER ${ }^{6}$, and (below) J. S. SWENTON and P. D. BARTLETT ${ }^{7}$ ]

cycloaddition of an enol ether to tetracyanoethylene ${ }^{6}$ and the addition of butadiene to a halogenated olefin ${ }^{7}$. Both reactions have been established to take place via intermediates. In the first case all four criteria discussed above have been applied to demonstrate the multistep nature. In the second example it is the stereochemistry of substituted dienes which shows the occurrence of an intermediate. In both reactions the reactivity can be related to the stability of the intermediate. As the rate-determining transition state should be close in energy to the intermediate, the explanation sounds reasonable and is in accordance with the Hammond principle. Does this rationalization also apply to concerted cycloadditions"' There is no simple means to determine the structure of transition states and, therefore, a simple and convincing explanation does not exist.

Figure 2 summarizes the arguments for the $\left({ }_{\pi} 2_{\mathrm{s}}+{ }_{\pi} 4_{\mathrm{s}}\right)$-cycloaddition of phenyl azide to an $\alpha, \beta$-unsaturated carboxylic ester and to an enamine ${ }^{8}$. The interpretation is the same as for the two-step $\left(\pi_{\pi}^{2}+\pi^{2}\right)$ additions. The 


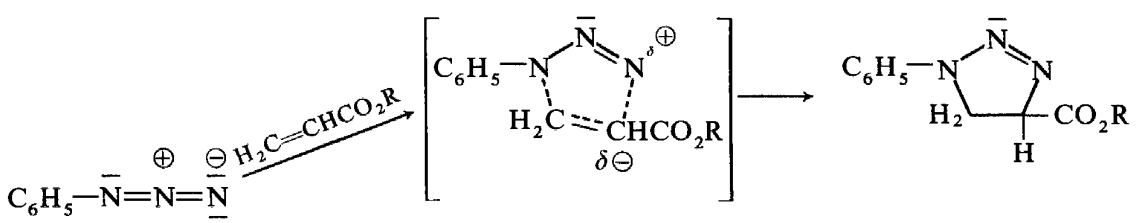

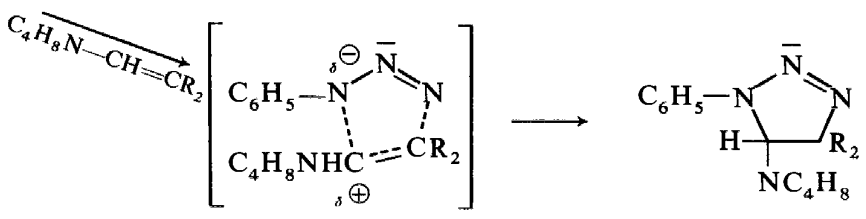

Figure 2. Partial charge separation in the transition state for cycloadditions of phenyl azide [After R. Huisgen, G. Szeimies and L. Moebius ${ }^{8}$ ]

transition state is thought to involve partial charge separation through unequal bond formation. The possibility of stabilizing these charges has been taken as a basis for reactivity and regioselectivity. The high reactivity of both dipolarophiles originates in the potential to stabilize a positive charge in the enamine and a negative charge in the carboxylic ester. This picture also demonstrates which of the new bonds is formed to a higher degree in the transition state. However, this argument fails to explain the following three facts (Figure 3): (1) A reactivity increase is observed in replacing an

1. Rate enhancement through conjugation

$$
\mathrm{CH}_{2}=\mathrm{CH}-\mathrm{CH}=\mathrm{CH}_{2}>\mathrm{H}_{2} \mathrm{C}=\mathrm{CH}_{2}
$$

2. Rate enhancement by a second substituent in 2-position

$$
\mathrm{RO}_{2} \mathrm{C}-\mathrm{CH}=\mathrm{CH}-\mathrm{CO}_{2} \mathrm{R}>\mathrm{H}_{2} \mathrm{C}=\mathrm{CH}-\mathrm{CO}_{2} \mathrm{R}
$$

3. Low reactivity of

$$
\mathrm{RO}_{2} \mathrm{C}-\mathrm{CH}=\mathrm{CH}-\mathrm{NR}_{2}
$$

Figure 3. Phenomena in concerted cycloadditions

unconjugated olefin by a conjugated one. (2) A drastic increase in reactivity is often found by introducing the same group in a monosubstituted olefin in the 2-position, for instance, replacing methyl acrylate by dimethyl fumarate. (3) In reactions which are accelerated both by electron-releasing and electronwithdrawing substituents the reactivity decreases if both kinds of substituents are incorporated in one molecule.

We have devised a simple perturbational model which is able to rationalize reactivity behaviour and also to enclose these hitherto poorly understood phenomena ${ }^{9,10}$. The Diels-Alder reaction ${ }^{11}$ and the 1,3-dipolar cycloaddition ${ }^{12}$, both $\left({ }_{\pi} 2_{s}+{ }_{\pi} 4\right)$ cycloadditions and as such thermally allowed concerted reactions ${ }^{4}$, will serve as models to develop and to demonstraie the power of this treatment. The procedure is based on one-electron perturbation theory. It is an application of the frontier electron theory of Fukui ${ }^{13}$. 


\section{PERTURBATIONAL MOLECULAR ORBITAI MODEL}

The essence of the $\mathrm{W}-\mathrm{H}$ rules for the Diels-Alder reaction is a correlation of the ground states of the reactants with the ground state of the product ${ }^{4}$. The Molecular Orbitals (MOs) of the diene and the dienophile which are occupied in their ground states are transferred to the ground state occupied molecular orbitals of the product. In order to obtain this result a mechanism is required in which diene and dienophile are placed above each other in two parallel planes.

The principle of conservation of orbital symmetry allows a prediction of the overall mechanism. It does not automatically lead to an explanation of reactivity. This can be included if one not only analyses the symmetry of the MOs of the reactants and the product, but also takes into account the energetics of the process. As soon as the interaction of diene and dienophile begins, the system is no longer described adequately by the MOs of the reactants. New molecular orbitals are formed which obey the symmetry of the assumed orientation complex ${ }^{14,15}$. This consideration is the basis for an explanation of substituent effects. In principle all MOs of proper symmetry of one reactant will interact with the molecular orbitals of the same symmetry of the other reactant. As interaction of occupied MOs does not yield a net energy change this interaction can be omitted. Therelore, only the interaction of occupied MOs of one molecule with unoccupied MOs of the other will bring a stabilization of the system. In order to simplify the procedure and to eliminate less important contributions the model is limited to the interaction of the HOMOs (Highest Occupied Molecular Orbitals) and LUMOs (Lowest Unoccupied Molecular Orbitals) of the reactants, i.e. the frontier orbitals ${ }^{13}$.

The procedure is demonstrated for the Diels-Alder addition in Figure 4. Assuming the depicted structure of the reaction complex (transition state) the HOMOs and LUMOs can be classified according to the symmetry plane. The HOMOs have the same symmetry as the LUMO of the reaction partner. The result is the formation of the new molecular orbitals $\psi_{1} \rightarrow \psi_{4}$, two of which are bonding and two antibonding. In this simple treatment the splitting of the interacting HOMO and LUMO is symmetrical, i.e. one orbital is raised in energy by the same amount as the other one is lowered. A second more important point concerns the magnitude by which the occupied MOs are lowered in energy. Second-order perturbation theory predicts this to be inversely proportional to the energy separation between the MOs involved. Therefore, the splitting is the greater the smaller is the energy difference. This means $\Delta E_{\mathrm{II}}>\Delta E_{\mathrm{I}}$ in Figure 4 . The result justifies the restriction to the HOMOs and LUMOs. The stabilization due to the interaction of stronger bonding occupied molecular orbitals of one reactant with unoccupied MOs of the other one is much smaller. This is the first result which leads us to a successful treatment of substituent effects. The next point concerns the influence of substituents on the energy of molecular orbitals. First-order perturbation theory is used for this purpose. Substituents are classified according to their electron-donating and electronwithdrawing power. Figure 5 shows the effect which these substituents will exercise on the MOs of ethylene. 

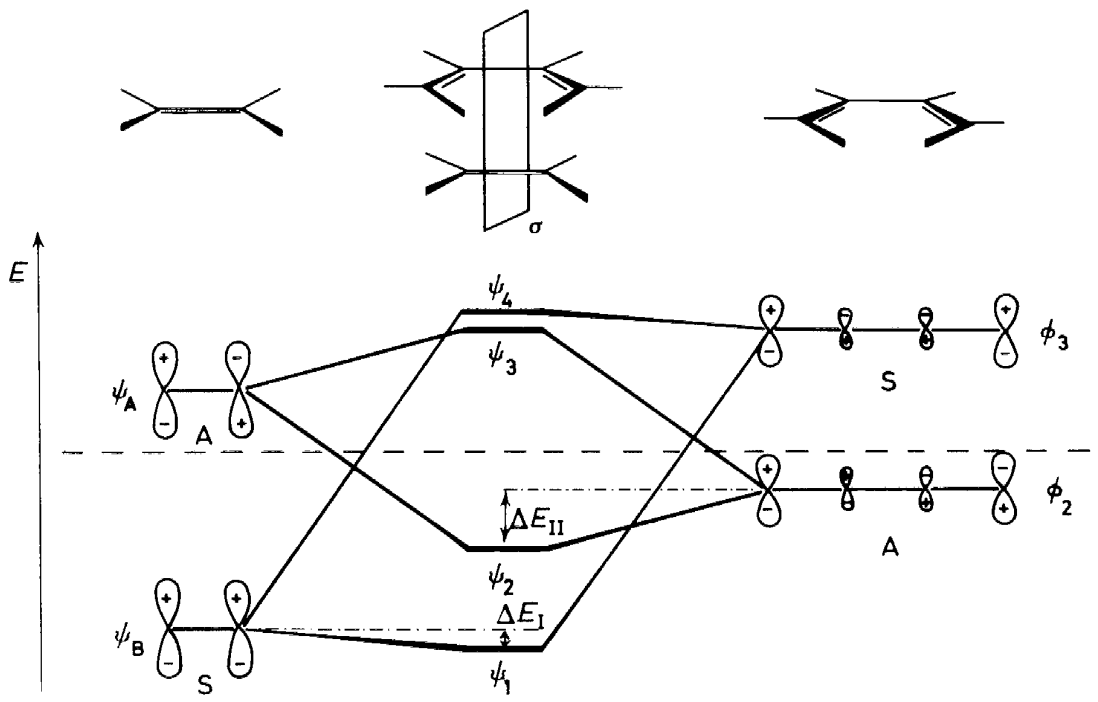

Figure 4. Perturbational interaction diagram for the Diels-Alder addition

An electron-withdrawing group (acceptor) lowers the energy proportional to the square of the atomic orbital coefficient at the centre where the substituent is attached. Conversely an electron donor substituent raises the energy of the molecular orbital. This classification of substituents includes both inductive and resonance effects. Thus the cyano group, the nitro group or the carboxylic group are electron-withdrawing substituents. On the other hand the amino group, the alkoxy group or the alkyl group donate electrons to the $\pi$-system. With these basic facts we are prepared to explain successfully the influence of substituents in cycloaddition reactions.

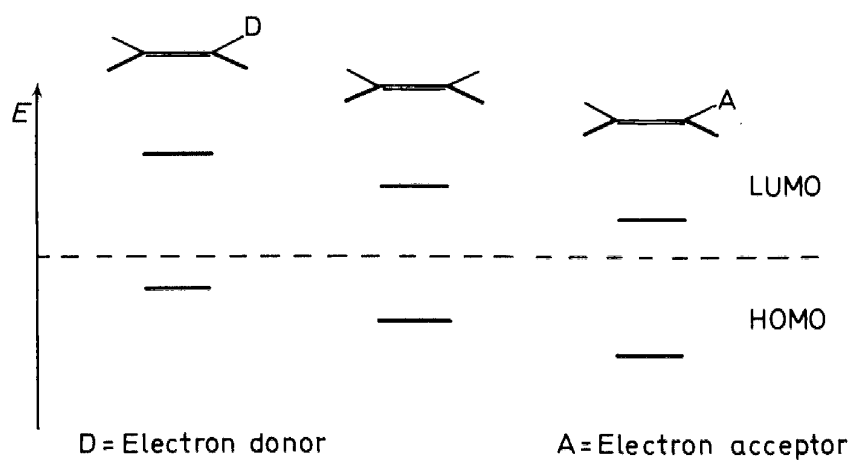

Figure 5. Effect of substituents on orbital energies 


\section{DIELS-ALDER ADDITION}

Figure 4 includes an unsymmetrical arrangement of HOMOs and LUMOs. The separation of $\mathrm{HOMO}_{\text {diene }}-\mathrm{LUMO}_{\text {dienophile }}$ is smaller than the other HOMO-LUMO distance. Therefore the former contributes more to the stabilization of the transition state and may be called the dominating interaction. Electron-withdrawing substituents in the dienophile will strengthen this dominating interaction and weaken the other one. It will be assumed that HOMO and LUMO dienophile are affected by the same amount. As a consequence the gain in stabilization through the increased interaction $\mathrm{HOMO}_{\text {diene }}-\mathrm{LUMO}_{\text {dienophile }}$ overrides the loss due to lengthening the second HOMO-LUMO separation. This follows from the inverse proportionality between stabilization and energy difference of interacting orbitals. Conversely, electron donor substituents will decrease the stabilization, i.e. the reactivity is lowered. Substitution in the diene will also affect the reactivity. As can be deduced from Figure 4 electron donor substituents will raise the HOMO and therefore will increase the reaction rate. The case under discussion is the 'normal' Diels-Alder addition. An example is shown in Figure $6^{16}$.

Normal Diels-Alder reaction

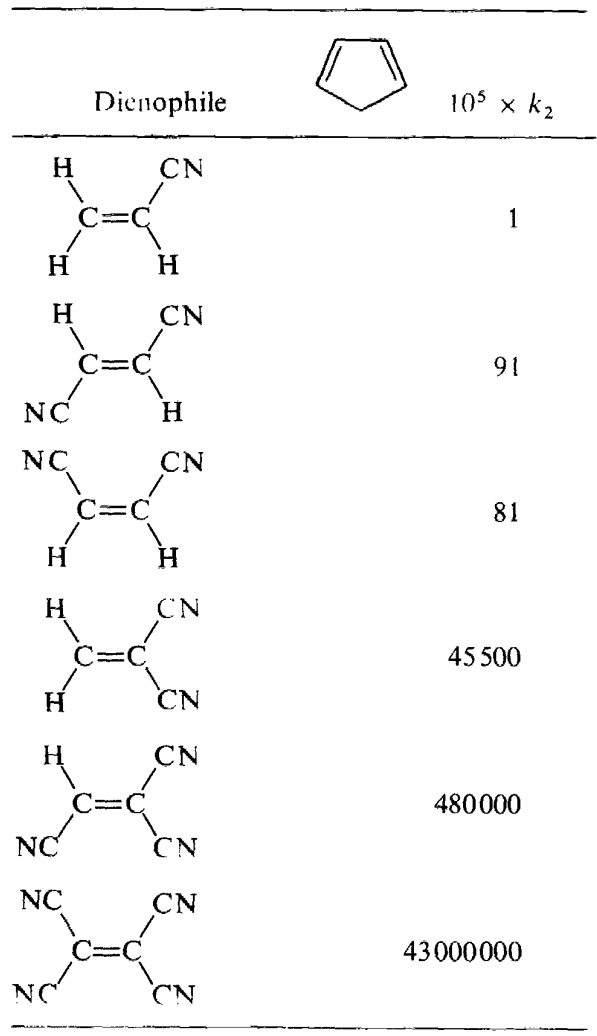

Figure 6. Rate constants for Diels-Alder additions of cyano-substituted dienophiles with cyclopentadiene [After J. SAI ER. H. WiEST and A. MIFI.FRT ${ }^{16}$ ] 


\section{ORBITAL ENERGY CONTROL OF CYCLOADDITION REACTIVITY}

The more cyano groups are attached to ethylene the higher the reactivity towards cyclopentadiene. There are seven powers of ten difference in the rate of reaction for acrylonitrile and tetracyanoethylene. The simple treatment can be used qualitatively only. This becomes apparent from the reactivity of the dicyano compounds. First-order perturbation theory starting with ethylene predicts that the 1,2-disubstituted olefins exhibit the same reactivity as 1,1-dicyanoethylene. Considering higher order effects or treating these molecules as a unit in Hückel molecular orbital calculations will show a difference for these dienophiles ${ }^{17}$.

\section{HOMO - LUMO ARRANGEMENTS}

TYPE I

Diene Dienophile
TYPE II

Diene Dienophile

$\Delta E=\Delta E^{\prime}$

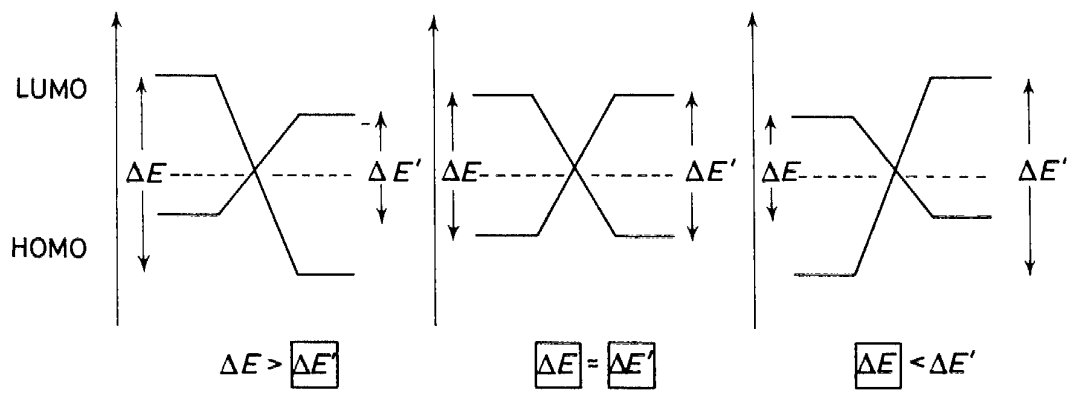

TYPE III

Diene Dienophile

Figure 7. HOMO-LUMO arrangements for the Diels-Alder reaction

Three possible arrangements of HOMOs and LUMOs are depicted in Figure 7. The first case (Type 1) corresponds to the normal Diels-Alder addition. Type III is just the inverse. Here $\mathrm{HOMO}_{\text {dienophile }}-\mathrm{LUMO}_{\text {diene }}$ is the determining interaction for the reactivity. Therefore either electronaccepting substituents in the diene or electron-donating groups in the dienophile will increase the rate of these cycloadditions. No reaction should be observed with electron-deficient olefins. This case is known experimentally as the Diels-Alder addition with inverse electron demand ${ }^{18}$. For Type II both HOMO-LUMO separations are similar, i.e. both have to be considered in a reactivity discussion. Any substitution either in the dienophile or in the diene will increase one HOMO-LUMO interaction and decrease the other one. Because of the inverse proportionality of the stabilization and the energy separation this implies rate enhancement by any kind of substitution in the diene or the dienophile.

Figure 8 gives an example of a Diels-Alder addition with inverse electron demand. The reaction of the substituted tetrazine with dienophiles leads after elimination of nitrogen to a pyridazine as the primary product ${ }^{19}$. The diene behaves as expected by first-order perturbation theory. The substitution of carbon by the more electronegative nitrogen lowers the orbital 
energies of the $\pi$-system and therefore moves the HOMO-LUMO arrangement from Type I in the direction of Type III. To obtain Type III dienes one has to substitute carbon atoms by atoms of higher electronegativity like nitrogen or oxygen. A further help would be strongly electron-accepting substituents.

Diels-Alder addition with inverse electron demand<smiles>CCOC(=O)C1N=NC(C(C)=O)C(C)(C)C1(C)C</smiles>

\begin{tabular}{l|c} 
Dienophile & $10^{5} \times k_{2}$ \\
\hline & \\
&
\end{tabular}

Figure 8. Rate constants for the Diels-Alder addition of tetrazine-3,6-dimethylcarboxylate [After J. SAUER and D. LANG ${ }^{19}$ ]

An experimental verification of the reactivity pattern of Type II has been given only recently by Konovalov ${ }^{20}$ (Figure 9). The reaction of substituted tetraphenylcyclopentadienones with 4-substituted styrenes can be rationalized in terms of Type II. The reactivity increase due to substitution in the dienophile is rather small. For Type II the energy gain through the increase of one HOMO-LUMO interaction will be compensated to a higher extent by the destabilization of the other frontier orbital interaction than for the other two reactivity types.

Two more aspects of Diels-Alder additions can be explained by the model. In Figure 10 the reactivity of tetracyanoethylene (TCNE) and maleic anhydride (MAA) is compared with the same set of substituted 
ORBITAL ENERGY CONTROL OF CYCLOADDITION REACTIVITY

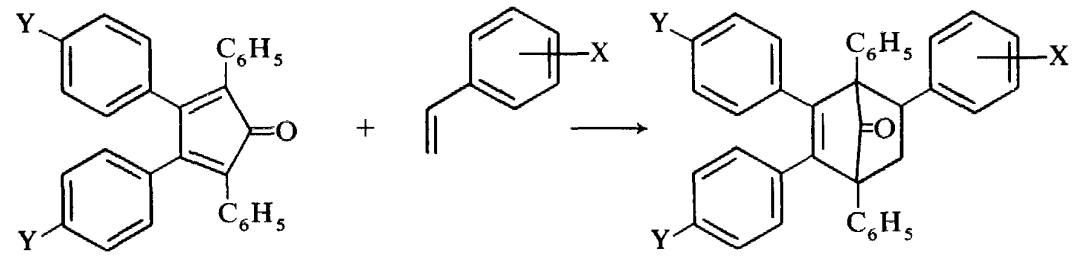

\begin{tabular}{|c|c|c|c|c|c|c|}
\hline & \multicolumn{6}{|c|}{$k_{2} \times 10^{6} 1 \mathrm{~mol}^{-1} \mathrm{~s}^{-1}$ (toluene, $\left.60^{\circ}\right)$} \\
\hline$x$ & $4-\mathrm{N}\left(\mathrm{CH}_{3}\right)_{2}$ & $4-\mathrm{OCH}_{3}$ & $\mathrm{H}$ & $4-\mathrm{Cl}$ & $3-\mathrm{NO}_{2}$ & $4-\mathrm{NO}_{2}$ \\
\hline $\mathrm{H}$ & 338 & 102 & 73 & 78 & 79 & 88 \\
\hline $\mathrm{CH}_{3} \mathrm{O}$ & 176 & 52.5 & 44.6 & 44.5 & 62 & 83 \\
\hline $\mathrm{N}\left(\mathrm{CH}_{3}\right)_{2}$ & 37.0 & 37.0 & 15.5 & 31.0 & 48 & 86 \\
\hline
\end{tabular}

Figure 9. Rate constants for the Diels-Alder addition of substituted tetraphenylcyclopentadienones with substituted styrenes [After A. I. KonOvalov and B. N. SOLOMONOV ${ }^{20}$ ]

butadienes $^{21}$. The reaction rate is highest for cyclopentadiene and lowest for butadiene. Introducing electron-donor substituents in the diene, like methyl groups or methoxy groups, increases the reactivity. The important information for our discussion is contained in the reactivity range for the two dienophiles. As can be deduced from the data, the range of rate constants of

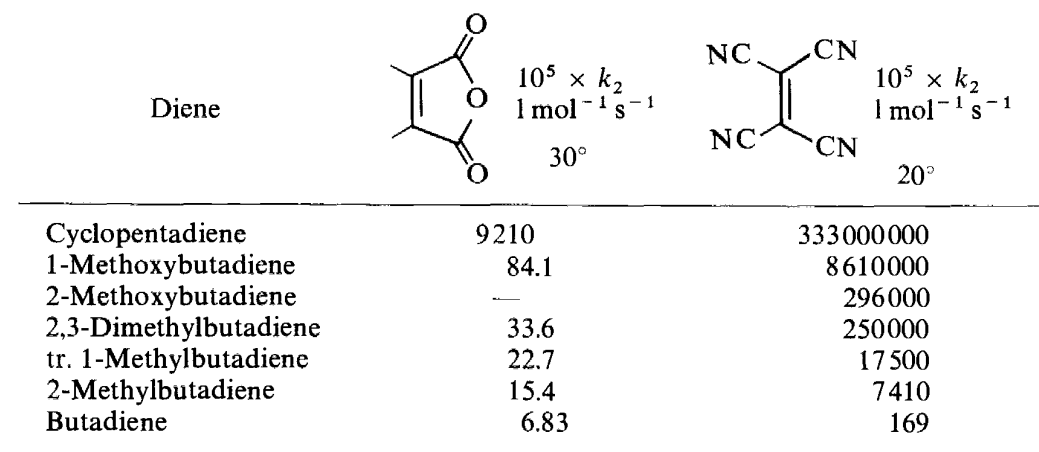

Figure 10. Rate constants for Diels-Alder additions of tetracyanoethylene and maleic anhydride with substituted dienes [After J. SAUER ${ }^{11}$ and C. RüCKER ${ }^{21}$ ]

TCNE exceeds that of MAA by a factor of $10^{3}$. The higher electron affinity of TCNE as compared to MAA yields a simple explanation ${ }^{22}$. The graphical demonstration is given in Figure 11. Due to the greater electron affinity of TCNE its LUMO is lower in energy than the LUMO of MAA. Consequently a decrease of the separation $\mathrm{HOMO}_{\text {diene }}-\mathrm{LUMO}_{\text {dienophile }}$ by introducing substituents in the diene will exert the greater rate enhancement in the case of TCNE. This example is a nice experimental verification of the inverse proportionality between orbital energy difference and rate acceleration.

A substituent in the 1-position of the diene affects the rate of reaction to a higher extent than this substituent will change the reactivity in the 2-position 

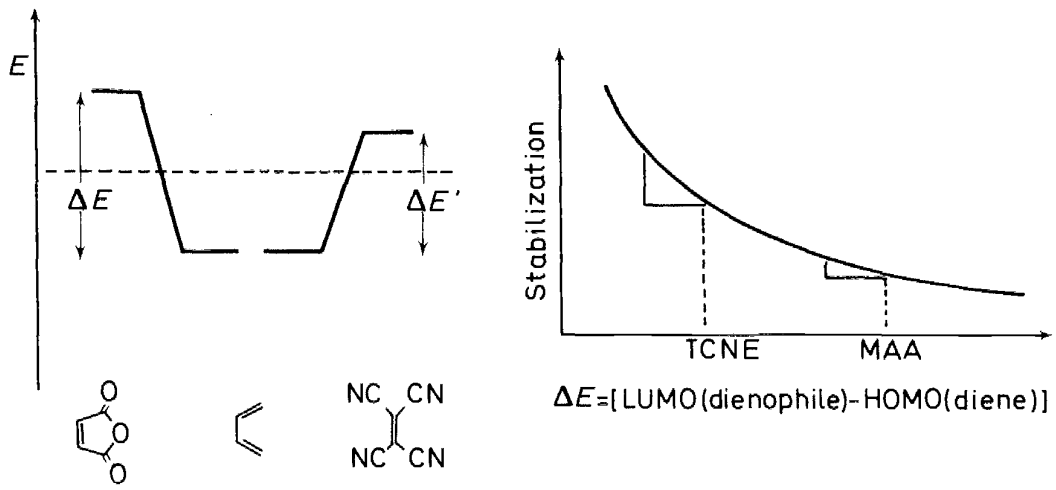

$\Delta E=[$ LUMO(dienophile)-HOMO(diene)]

Figure 11. Comparison between the reactivity of tetracyanoethylene and maleic anhydride

(Figure 12) ${ }^{21}$. A few examples are given in Figure 12. In each case the reaction rate of the 1-substituted diene exceeds the 2-substituted analogue. The difference ranges between a factor of two and almost thirty for the methoxy butadienes. This phenomenon can be explained by the influence which these substituents will exert on the HOMO and LUMO of butadiene. The perturbation of the orbital energies is proportional to the square of the

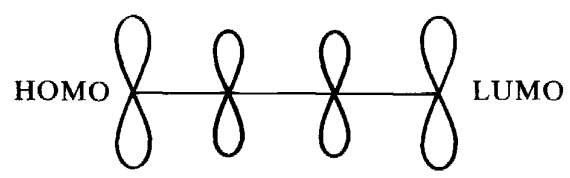

\begin{tabular}{|c|c|c|c|c|c|}
\hline Diene & $10^{3} \times k_{2}$ & Diene & $10^{3} \times k_{2}$ & Diene & $10^{3} \times k_{2}$ \\
\hline $\mathrm{CH}$ & 175 & $\mathrm{OCH}$ & 86100 & & 652 \\
\hline & 74.1 & $\mathrm{H}_{3} \mathrm{CO}_{2}$ & 2900 & & 323 \\
\hline
\end{tabular}

Figure 12, Reactivity of 1- and 2-substituted dienes towards tetracyanoethylene [After C. RÜCKER ${ }^{21}$ ]

atomic orbital coefficient in the MOs. The absolute values of the eigenvector coefficients are the same for HOMO and LUMO butadiene at the different positions as is shown at the top of Figure 12. The contribution of the carbon atom in 1-position is greater and therefore the orbital energy will be shifted to a greater extent by a substituent at this carbon atom. 


\section{1,3-DIPOLAR CYCLOADDITIONS}

The diversity of 1,3-dipolar cycloadditions finds its systematization within the framework of the perturbational reactivity model. The classification of 1,3-dipoles is given in Figure 13. Two types of 1,3-dipoles are distinguished : (1) Dipoles of the allyl anion type, and (2) Dipoles of the propargenyl allenyl

\section{1,3-DIPOLAR CYCLOADDITIONS}<smiles></smiles>

1,3-Dipoles of the Allyl Anion Type

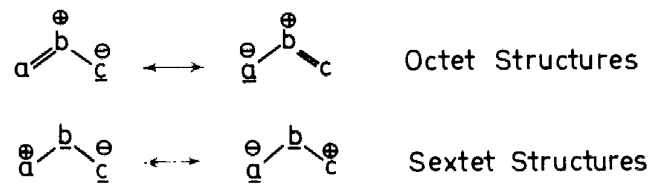

1,3- Dipoles of the Propargenyl-Allenyl Anion Type

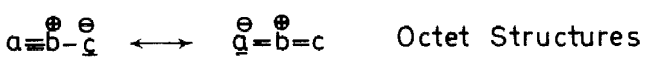

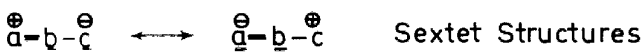

Figure 13. 1,3-Dipoles of allyl anion type and 1,3-dipoles of the allenyl propargenyl anion type

anion type. The additional double bond in the latter case is of no importance for the reactivity in cycloadditions. The reactive part of a 1,3-dipole is a $4 \pi$ allyl system ${ }^{23}$. When the $4 \pi$-electrons are spread over a three-carbon skeleton, the reactive particle is an allyl anion. Figure 14 shows the basis of the reactivity treatment.

The activated complex of the cycloaddition is assumed to consist of an arrangement of 1,3-dipole and dipolarophile in two parallel planes. The complex has a symmetry plane $\sigma$ according to which HOMOs and LUMOs can be classified as symmetric or antisymmetric. Both HOMO-LUMO pairs possess the correct symmetry for interaction ${ }^{23}$. The frontier orbital arrangement corresponds to the all-carbon allyl system and ethylene. The HOMO-LUMO separation is shortest between $\mathrm{HOMO}_{\text {allyl }}$ and $\mathrm{LUMO}_{\text {dipolarophile, }}$ thus corresponding to Type I of the classification of the Diels-Alder addition. Accordingly one would expect electron-deficient olefins such as tetracyanoethylene or methyl azodicarboxylate to be very active cycloaddition partners. Electron-rich olefins should show no reactivity towards this anion. The scarce experimental evidence which demonstrates the possibility of cycloaddition between allyl anions and olefins ${ }^{24,25}$ does not allow a classification according to the most reactive olefins. However, 

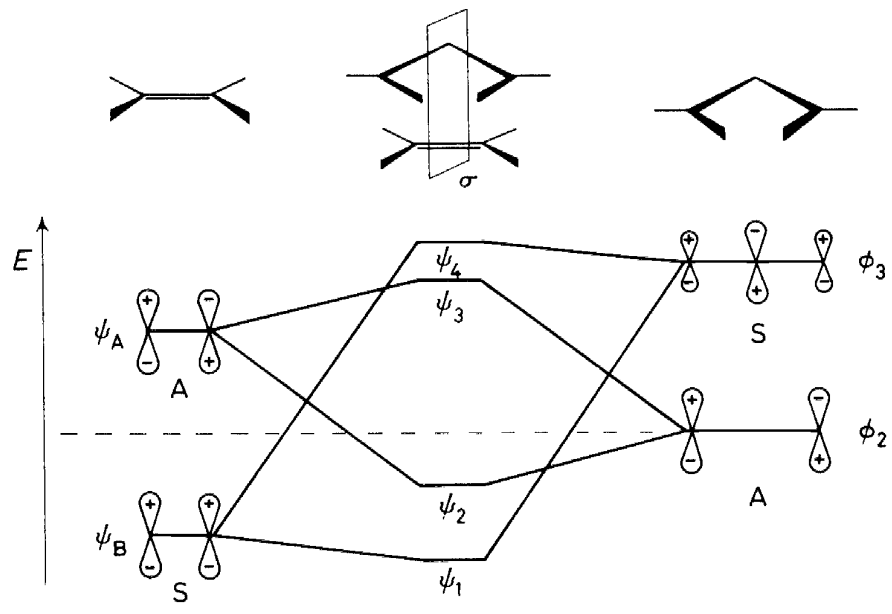

Figure 14. Perturbational interaction diagram for 1,3-dipolar cycloadditions

there are 1,3-dipoles which obey the rules of Type I. They are derived trom the carbon allyl system by introduction of nitrogen. One of these systems is diphenyldiazomethane (Figure 15$)^{26}$. The reactivity increases with the number and power of electron-withdrawing groups in the olefin as the kinetic data clarify. One should especially notice the difference between methyl acrylate and dimethyl fumarate.

In contrast to the Diels-Alder addition, Type II of the classification has been known for some time in 1,3-dipolar cycloadditions. The azide system which is obtained by substitution of the carbon atom of diazoalkanes by nitrogen belongs to this category. The electronegativity difference between carbon and nitrogen is sufficient to convert a 1.3-dipole of Type I to Type II $^{8}$.

\begin{tabular}{cc}
$\left(\mathrm{C}_{6} \mathrm{H}_{5}\right)_{2} \stackrel{\ominus}{\mathrm{C}}-\mathrm{N}=\mathrm{Ni}$ & \\
$+\mathrm{C}=\mathrm{C}=$ & $10^{5} \times k_{2}\left[1 \mathrm{~mol}^{-1} \mathrm{~s}^{-1}\right]$ \\
\hline Dipolarophile & 1.40 \\
\hline $\mathrm{H}_{2} \mathrm{C}=\mathrm{CH}-\mathrm{C}_{6} \mathrm{H}_{5}$ & 434 \\
$\left.\mathrm{H}_{2} \mathrm{C}=\mathrm{CH}-\mathrm{CN}_{5}\right)_{2}$ & \\
$\mathrm{H}_{2} \mathrm{C}=\mathrm{CH}-\mathrm{CO}_{2} \mathrm{C}_{2} \mathrm{H}_{5}$ & 707 \\
$\mathrm{CH}_{3} \mathrm{O}_{2} \mathrm{C}-\mathrm{HC}=\mathrm{CH}-\mathrm{CO}_{2} \mathrm{CH}_{3}$ & 2450 \\
\hline
\end{tabular}

Figure15. Rate constants for cycloadditions of diphenyldiazomethane [After R. HuisGEN, H. STANGL, H. J. STURM and H. WAGENHOFER ${ }^{26}$ ] 


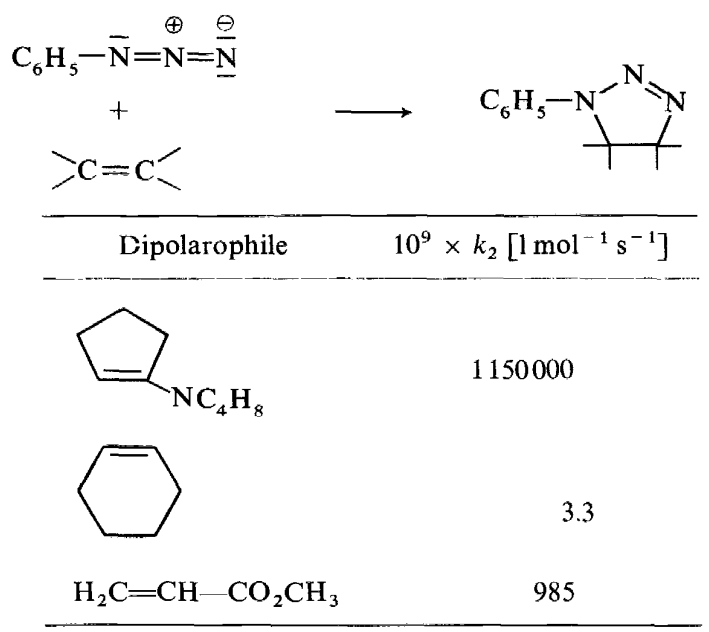

Figure 16. Rate constants for cycloadditions of phenyl azide [After R. HUISGEN, G, SzeImies and L. MoEBIUS ${ }^{8}$ ]

The kinetic data in Figure 16 display the high reactivity of phenyl azide towards enamines, the low reactivity towards normal alkenes such as cyclohexene and the rate increase when $\alpha, \beta$-unsaturated esters are partners in this cycloaddition. Thus, the reactivity shows a minimum for the common alkene, while electron-releasing as well as electron-attracting substituents increase the rate constant. A second example is the reaction between benzonitrile oxide and different olefins to form $\Delta^{2}$-isoxazolines ${ }^{27,28}$. A minimal reactivity is found for ethylene while both $\beta$-pyrrolidino styrene and methyl acrylate do react faster (Figure 17). The effect of a substituent on the rate is smaller in this case than for phenyl azide. This aspect will be dealt with later.

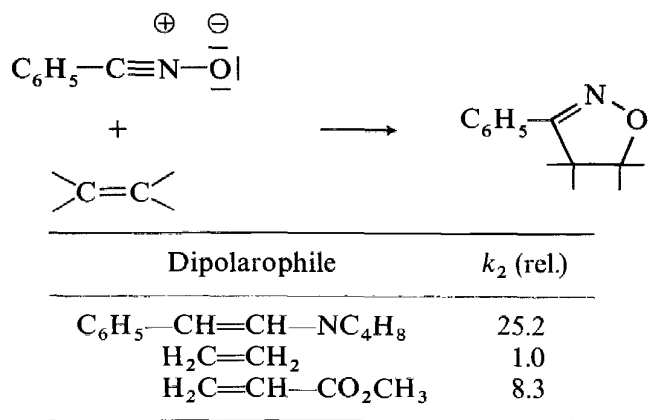

Figure 17. Relative rate constants for cycloadditions of benzonitrile oxide [After K. BAST, M. ChristL, R. HuISGEN and W. MACK ${ }^{27}$ ]

Does Type III of the reactivity scale exist in 1,3-dipolar cycloadditions? Even though there has been revived discussion about the mechanism of ozonolysis lately ${ }^{29,30}$, for most of these reactions a 1,3-dipolar addition to form a 1,2,3-trioxolane (Figure 18) offers the best description of the primary 
REINER SUSTMANN

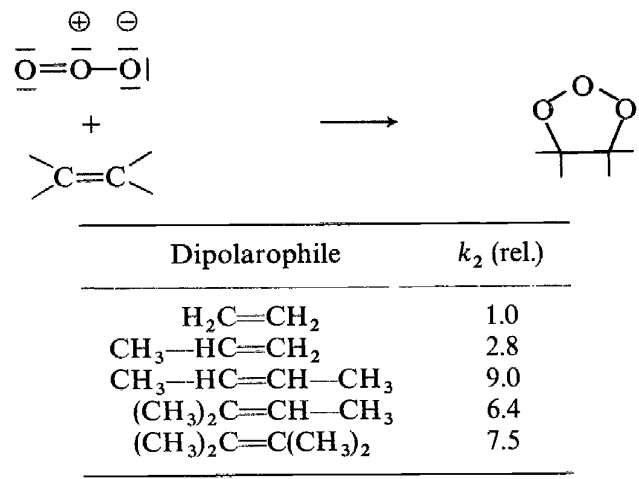

Fiqure 18. Relative rates of ozonolysis [After T. VRBASKI and R. J. CvETANović ${ }^{31}$ ]

step. The reactivity pattern of methyl-substituted olefins proves the superiority of electron-rich olefins in these reactions ${ }^{31}$. A multiplicative effect on the rate is found by going from propylene to butene-2. The reactivity decreases again for trimethylethylene and tetramethylethylene. One can interpret this in terms of a steric effect. The more the olefinic double bond is screened by substituents the harder it is for the 1,3-dipole to enter the reaction. That this interpretation seems to be correct is demonstrated by the failure of tetra-tert.-butylethylene to undergo ozonolysis. This also points to a restriction of the perturbational treatment. Steric effects are not taken into account, because properties of the ground state of the isolated molecules serve as basis for the reactivity. It might well be that steric effects become important in a later stage of the reaction, i.e. on approaching the transition state. Steric effects certainly cannot be evaluated by this $\pi$-electron approach.

Hammett correlations in azide cycloadditions
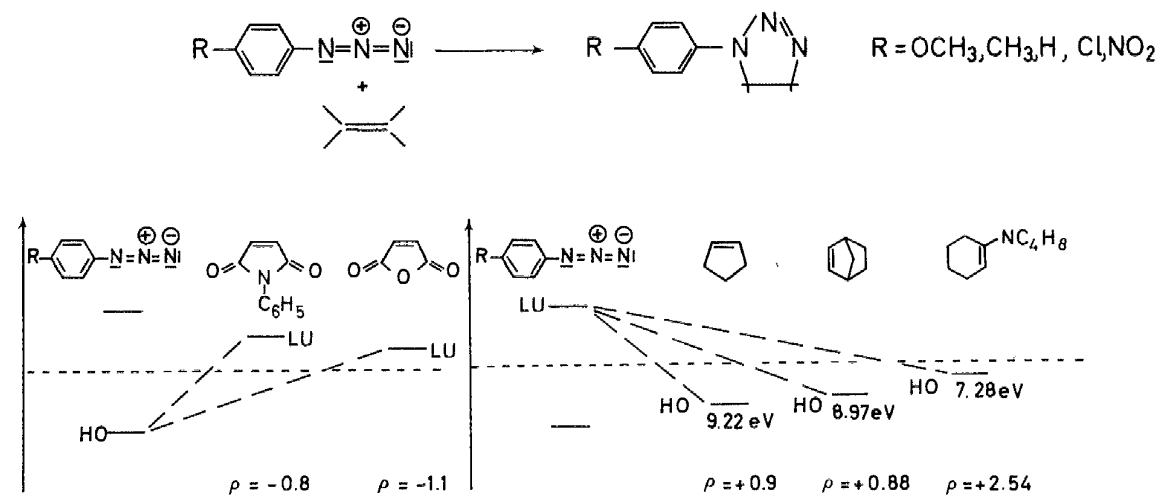

$<O$ HOMOdipole-LUMOolefin dominant; $\rho>0$ LUMOdipole-HOMO olefin dominant

Figure 19. Hammett correlations in 1,3-dipolar cycloadditions [After R. HUISGEN, G. SzeIMIEs and L. MOEBIUS ${ }^{8}$ ] 
There is one more result which finds a simple explanation within our model $^{32}$. This is the influence of 4-substitution in phenyl groups, i.e. the explanation of Hammett correlations in these cycloadditions. Much effort has been spent to obtain such correlations and to interpret their significance for the mechanism. One illuminating example is given in Figure 19, the reaction of 4-substituted phenyl azides with olefins ${ }^{8}$. In the case of maleic anhydride (MAA) and $N$-phenyl maleimide (NPM) a negative $\rho$-value of -0.8 and -1.1 is obtained whereas the other olefins do give a positive $\rho$-value. The very high $\rho=+2.5$ is observed for the electron-rich pyrrolidinocyclohexene. A negative $\rho$-value implies that this reaction takes place preferentially with the 4-methoxyphenyl azide and not with 4-nitrophenyl azide. On the other hand 4-nitrophenyl azide is the better 1,3-dipole for electron-rich olefins. Thus, the sign of the $\rho$-value allows us to recognize the dominant HOMO-LUMO interaction. For MAA and NPM the negative value indicates that $\mathrm{HOMO}_{\text {dipole }}-\mathrm{LUMO}_{\text {dipolarophile }}$ is reactivity-determining and for the other olefins the positive value shows $\mathrm{LUMO}_{\text {dipole }}{ }^{-}$ $\mathrm{HOMO}_{\text {dipolarophile }}$ as dominant. In several cases non-linear Hammett plots have been found for 1,3-dipolar cycloadditions ${ }^{33}$. This occurs if Type II of the orbital arrangement (Figure 7) is realized for the unsubstituted phenyl ring. In this instance any substitution of hydrogen by electron-donor substituents or electron-accepting substituents will accelerate the reaction. A non-linear plot of $\log k$ versus $\sigma$ is obtained. One therefore may ask whether Hammett plots can be interpreted in terms of charge separation in the transition state of cycloadditions? This problem will be discussed further.

At this point the facts which were cited at the beginning as somewhat mysterious are open to interpretation. Figure 20 shows at the top the rate increase by extension of the $\pi$-system. Hückel molecular orbital theory predicts the gap between HOMO and LUMO in conjugated olefins to shrink. Therefore the $\mathrm{HOMO}_{\text {dipole }}-\mathrm{LUMO}_{\text {dipolarophile interaction and the }}$ $\mathrm{LUMO}_{\text {dipole }}-\mathrm{HOMO}_{\text {dipolarophile }}$ interaction become stronger, and rate enhancement is the result. The influence of a second substituent (methyl acrylate versus dimethyl fumarate) increases the reactivity sometimes by an almost multiplicative factor. This can be understood because the second substituent again will influence HOMO and LUMO energies in the same direction as the first one.

Now consider the third point which could not be explained by the model of partial charges in the transition state. Let us assume a cycloaddition of Type II where electron-donating and electron-withdrawing substituents in the dipolarophile both activate the reaction. The incorporation of both types of substituents in one olefinic dipolarophile has no or negligible effect on reactivity. The answer is : the influence of one substituent is compensated by that of the other one. This interpretation is supported by the half-wave oxidation potentials which can be taken as a measure of HOMO energies. The effect of an amino group at an olefin is at least partially cancelled by an electron-accepting group ${ }^{34}$.

The reactivity of 1,3-dipoles can be rationalized (Figure 21). The consecutive substitution of carbon by the more electronegative elements nitrogen and oxygen will lower the molecular orbital energies of the allyl system. The structure of $\mathrm{HOMO}_{\text {allyl }}$ shows that only terminal substitution will 
1. Increase of reactivity through conjugation

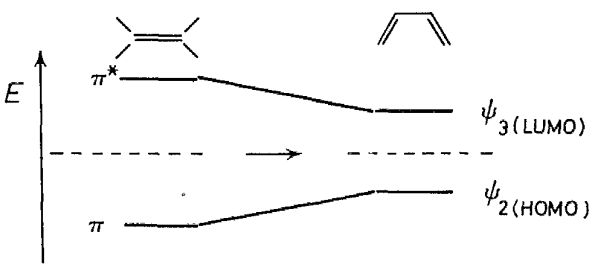

2. Multiplicative effect of a second substituent

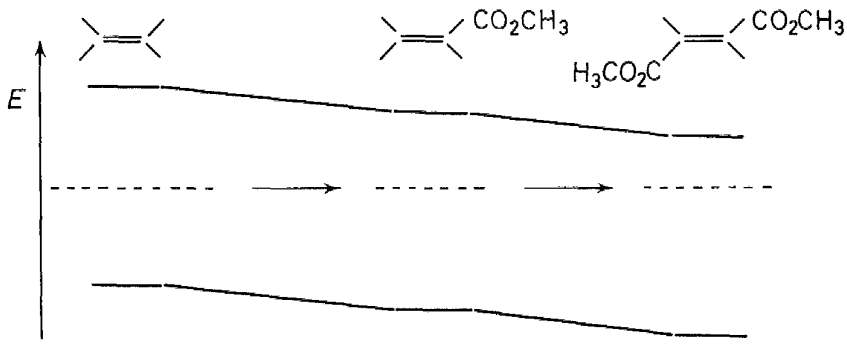

3. Levelling effect of an electron-withdrawing and an electron-releasing substituent

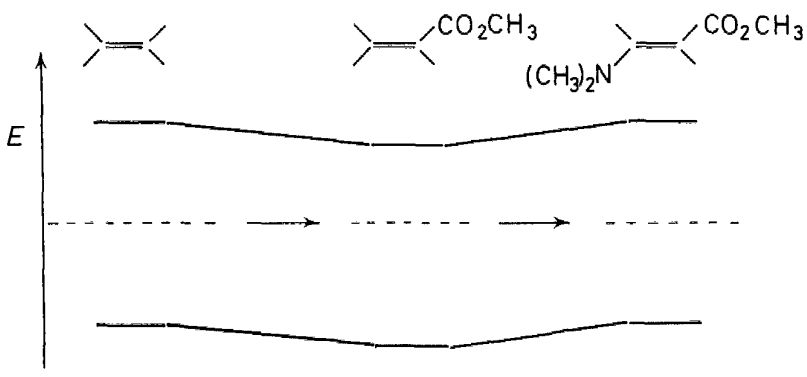

Figure 20. Perturbational rationalization of some phenomena in concerted cycloadditions

influence its energy while the LUMO is lowered mainly by substitution in the middle position. Experimentally the nitrile ylides and diazoalkanes are of Type I. The amount of substitution is not yet sufficient to alter reactivity behaviour in the direction of Type II. However, the replacement of the remaining carbon atom of the diazoalkane system by nitrogen, i.e. when the azide system is generated, changes the reactivity pattern to Type II. Also the substitution of a terminal carbon atom in the nitrile ylide system by oxygen or nitrogen has the same effect of transforming the reactivity. Under these auspices it is no wonder that ozone and nitrous oxide are two of the few 1,3-dipoles which belong to Type III. Substitution of all allyl carbon atoms by the most electronegative atom of the series carbon, nitrogen and oxygen or replacing two of these by oxygen and one by nitrogen realizes this reac- 


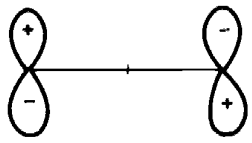

HOMO

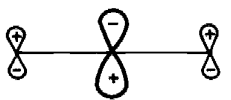

LUMO

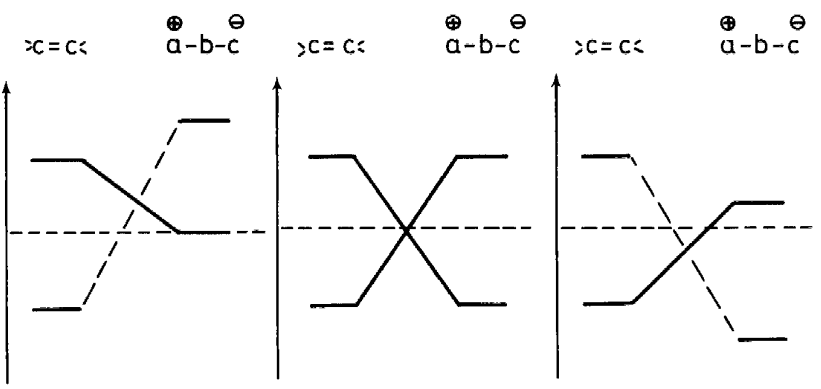

\begin{tabular}{|c|c|c|}
\hline I & II & III \\
\hline 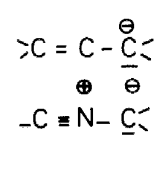 & 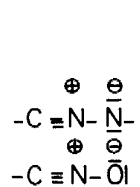 & \\
\hline $\mathrm{N}=\stackrel{\oplus}{N}-\stackrel{\ominus}{\mathrm{C}}=$ & $-\underline{N}=\stackrel{\oplus}{N}=\stackrel{\ominus}{\underline{N}}$ & 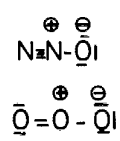 \\
\hline
\end{tabular}

Figure 21. Systematization of 1,3-dipolar cycloadditions

tivity type. One can imagine that substituents in the heteroallyl system will have additional effects on the reactivity.

\section{GENERALIZATION OF THE REACTIVITY MODEL}

The last section will be concerned with the problem of how to obtain a more quantitative treatment of substituent effects. In the foregoing sections a combination of first-order and second-order perturbation theory was applied. The stabilization due to interaction of the HOMO and LUMO was a second-order effect while the treatment of substituent effects was based on first-order perturbation theory. The mathematical expression for the secondorder energy change is shown in Figure 22. 


$$
\Delta E=\frac{\left[\mathrm{c}_{\mathrm{Ho} 1}, \mathrm{c}_{\mathrm{Lu} 1}+\mathrm{c}_{\mathrm{Ho} 2}, \mathrm{c}_{\mathrm{Lu} 4}\right]^{2} \beta^{2}}{E_{\mathrm{Ho}(\text { Dienophile })}-E_{\mathrm{Lu}(\text { Diene })}}+\frac{\left[\mathrm{c}_{\mathrm{Ho1}} \mathrm{c}_{\mathrm{Lu} 1^{\prime}}+\mathrm{c}_{\mathrm{Ho} 4} \mathrm{c}_{\mathrm{Lu} 2}\right]^{2} \beta^{2}}{E_{\mathrm{Ho}(\text { Diene })}-E_{\mathrm{Lu}(\text { Dienophile })}}
$$

Contribution from the eigenvector coefficients in the numerator is assumed constant, i.e. independent of the structure of diene and dienophile.

$$
E=K \beta^{2}\left[\frac{1}{E_{\mathrm{Ho}(\text { Dienophile })}-E_{\mathrm{Lu}(\text { Diene })}}+\frac{1}{E_{\mathrm{Ho}(\text { Diene })}-E_{\mathrm{Lu}(\text { Dienophile })}}\right]
$$

Figure 22. Second-order energy change for the Diels-Alder addition

The two terms of the equation for $\Delta E$ refer to the HOMO-LUMO interactions. In the denominator one finds the difference of orbital energies. The numerator shows products of the atomic orbital coefficients $c$ at the centres where the new bonds are formed together with the resonance integral $\beta$ as measure for the strength of the interaction. In order to recognize the salient features of the expression some simplifications are introduced. The justification for this approach will be discussed later. First it will be assumed that $\beta$ will take a common value in all cases under discussion. The second drastic simplification is to assume the numerator to be constant for the diversity of systems. This finds a certain justification in the kind that the treatment will be used for. Normally one studies the reaction of a constant diene or dipole with a series of olefins or vice versa. Therefore, the contribution of one reaction partner in the numerator will remain constant throughout the series. The application of the simplified expression to Type II of the reactivity scale leads to the function of Figure $23^{35}$.

Both HOMO-LUMO separations are taken as equal and will be given the symbol $D$. A substituent, either electron-donating or electron-accepting, will alter the difference by a certain amount $x$. One separation will be decreased by $+x$, the other one increased by $-x$. The graphical representation is shown in the lower part of Figure 23. The total stabilization is a superposition of two hyperbolae leading to a $U$-shaped curve. Depending on the HOMO-LUMO separations the actual structure may resemble a more or less deformed $U$-shape or in the limiting case, where only one HOMOLUMO interaction dominates, degenerate to one of the two branches. Thus a whole spectrum of different behaviour may be obtained.

The biggest change in rate by a substituent occurs when one interaction prevails and, furthermore, when the orbital energy separation is small for the unsubstituted molecules. The reaction of tetracyanoethylene with substituted butadienes is such a case. If the separation becomes greater then the same substituents will provoke smaller rate effects. Examples may be envisaged where both HOMO-LUMO separations are equally important and rather large. Then substitution will cause only slight rate acceleration. The reaction between the substituted tetraphenylcyclopentadienone with substituted styrenes may be such a case. 
TYPE II

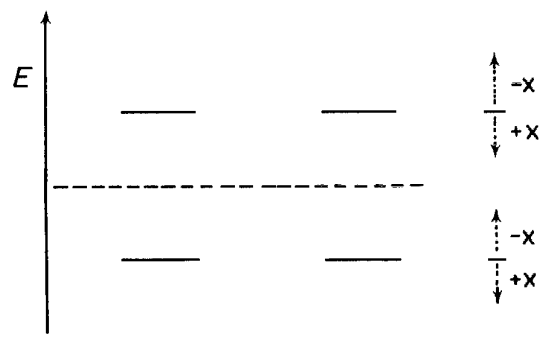

$$
E_{\mathrm{Ho}}-E_{\mathrm{Lu}^{\prime}}=E_{\mathrm{Ho}^{\prime}}-E_{\mathrm{Lu}}=D
$$

$\Longrightarrow \Delta E=K \beta^{2}\left[\frac{1}{D+x}+\frac{1}{D-x}\right]$

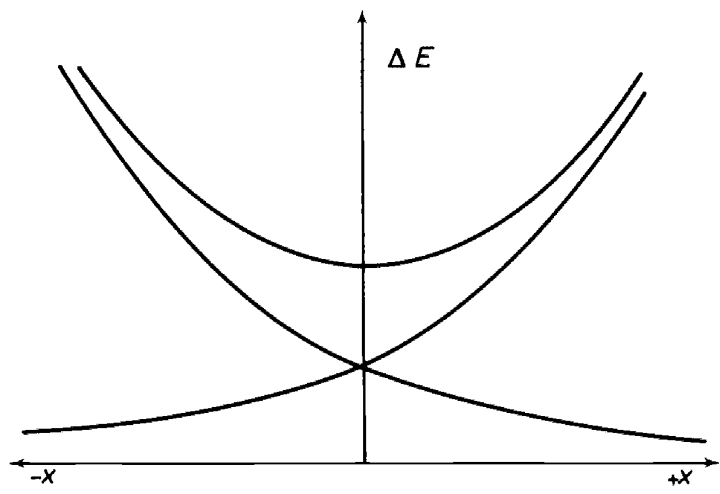

Figure 23. Simplified treatment of second-order perturbations

Even though the most important contribution of the stabilization stems from the denominator of the expression, the qualitative discussion does not yet show how quantitative these correlations are. To get information on this point the energies of HOMOs and LUMOs have to be known. The most reliable method to measure the energies of HOMOs is photoelectron spectroscopy (PE spectroscopy). However, one has to admit the validity of Koopman's theorem, an assumption which might not always be fulfilled ${ }^{36}$. The energies of LUMOs can be obtained from the electron affinity of molecules. The PE-spectra of a number of relevant olefins and dienes have been studied by others ${ }^{37}$ and also in our group ${ }^{38,39}$. Electron affinities are known only scarcely.

The derived expression was tested for the reaction of tetracyanoethylene (TCNE) and maleic anhydride (MAA) with substituted dienes ${ }^{40}$. The reactivity is dominated by the energy separation $\mathrm{HOMO}_{\text {diene }}-\mathrm{LUMO}_{\text {dienophile }}$. The contribution from the second interaction must be small and will be neglected. Thus one needs to know the HOMO energies of the dienes and 
the LUMO energies of the olefins. The electron affinities of TCNE and MAA are $1.7 \mathrm{eV}$ and $0.5 \mathrm{eV}$ respectively ${ }^{22}$. If one now plots the logarithms of the rate constants versus the HOMO-LUMO difference one should obtain a hyperbola. The result is shown in Figure 24.

DIELS-ALDER ADDITIONS OF TETRACYANOETHYLENE匹 and MALEIC ANHYDRIDE•

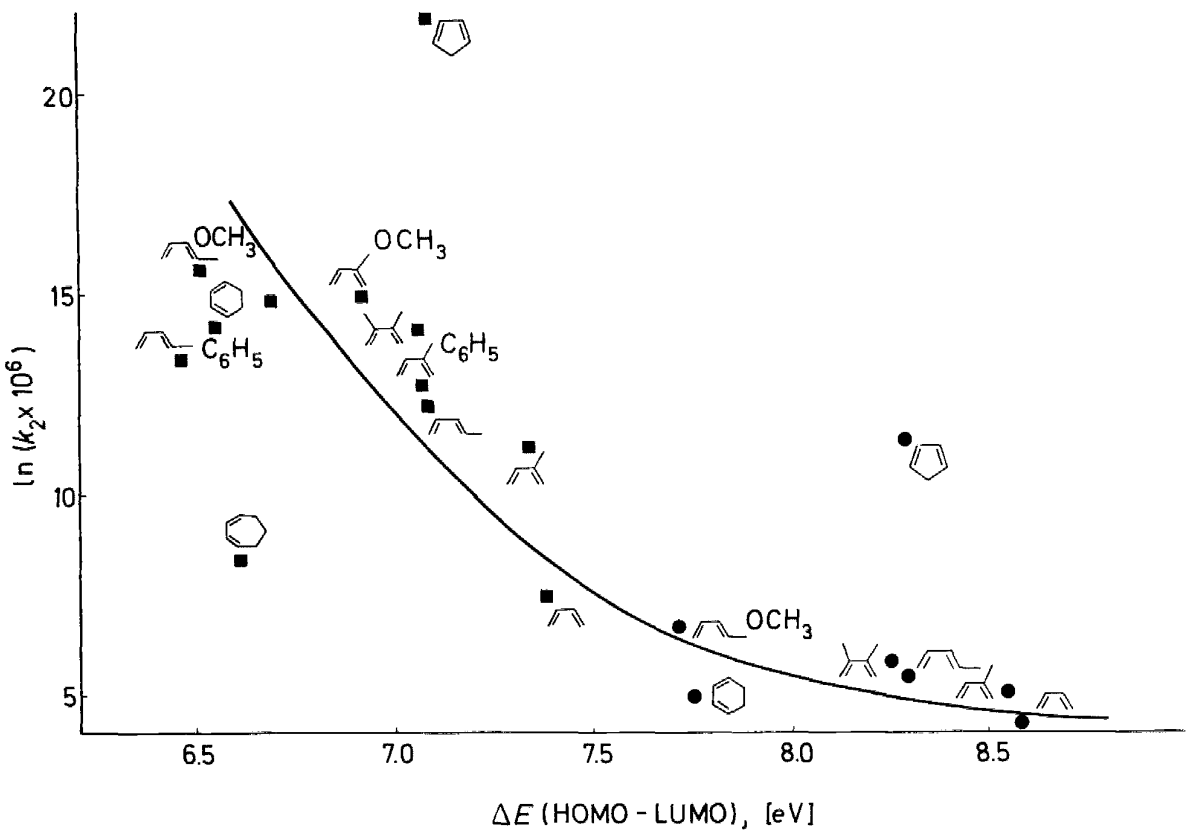

Figure 24. Correlation of HOMO-LUMO separations with $\ln k_{2}$ values for the Diels-Alder addition of tetracyanoethylene and maleic anhydride with substituted dienes

A curve of the expected shape is found. However, there are some discrepancies. Cyclopentadiene reacts faster than it should by its HOMO energy. This can be explained by the fixation of this diene in the cisoid conformation, whereas most of the others occur only to a small percentage in this conformation. With this correction for cyclopentadiene, the correlation improves. There are more stray shots. The failure of cycloheptadiene to show a better correlation may be explained by a steric effect. Taking all this together, the correlation is only a semiquantitative one. However, this is no surprise. Two major restrictions have to be remembered: (1) The extreme simplification of the mathematical expression, and (2) A ground state property of the reactants is used for the correlation. Cyclopentadiene illustrates that the 1,4-distance in dienes is an important factor and cycloheptadiene points to the possibility of steric effects. Thus, a good correlation could only be expected if other factors than orbital energies are negligible.

A second example may illustrate this ${ }^{35}$. The reaction of phenyl azide with a number of olefins belongs to Type II and, therefore, one needs in principle four orbital energies. These are difficult to obtain. Figure 25 explains the 

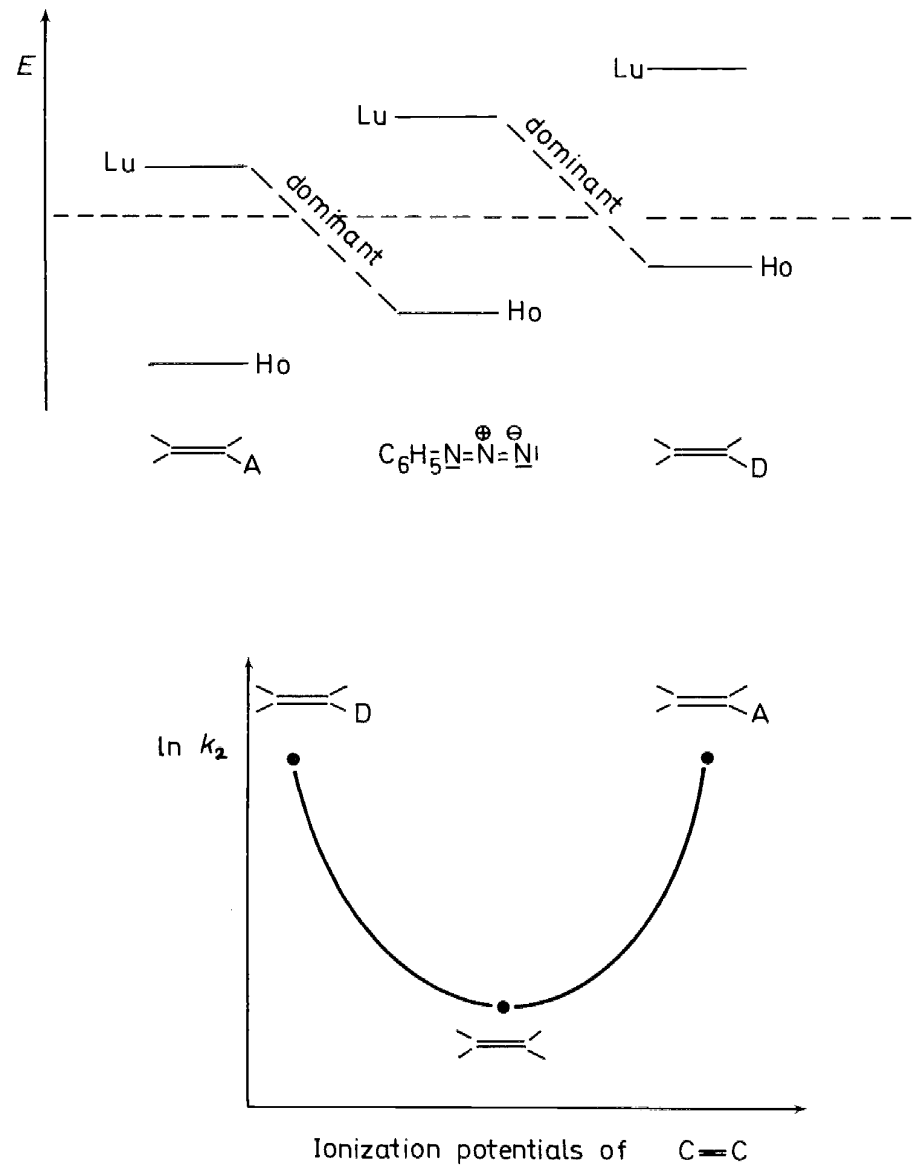

Figure 25. The $\mathrm{U}$-shaped curve for the correlation of HOMO energies with $\ln k_{2}$ values in Type II cycloadditions

procedure. Phenyl azide is kept constant as reaction partner. Instead of using the difference $\mathrm{HOMO}_{\text {olefin }}-\mathrm{LUMO}_{\text {dipole, }}$, one can resort to the

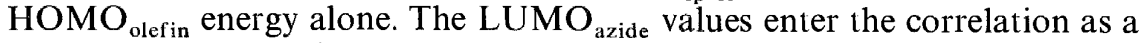
constant. The same holds true for the second interaction. Here the knowledge of the LUMO energy of the olefin would be sufficient. However, these are not normally known. To achieve the correlation, we may recall that HOMOs and LUMOs will be shifted in the same direction by substitution. Therefore the variation of HOMO energy should be reflected in corresponding shifts of LUMO energies. This means that a correlation of the HOMO(olefin) energies alone should yield a $U$-shaped curve as is shown in Figure 25.

Logarithms of the rate constants of phenyl azide are correlated with the ionization potentials of a number of olefins in Figure $26^{35}$. As for Diels-Alder addition, only a semiquantitative relation is gained. Again a number of olefins deviate from a good correlation. Besides the drastic simplifications this may help us to recognize other factors important in cycloadditions. 


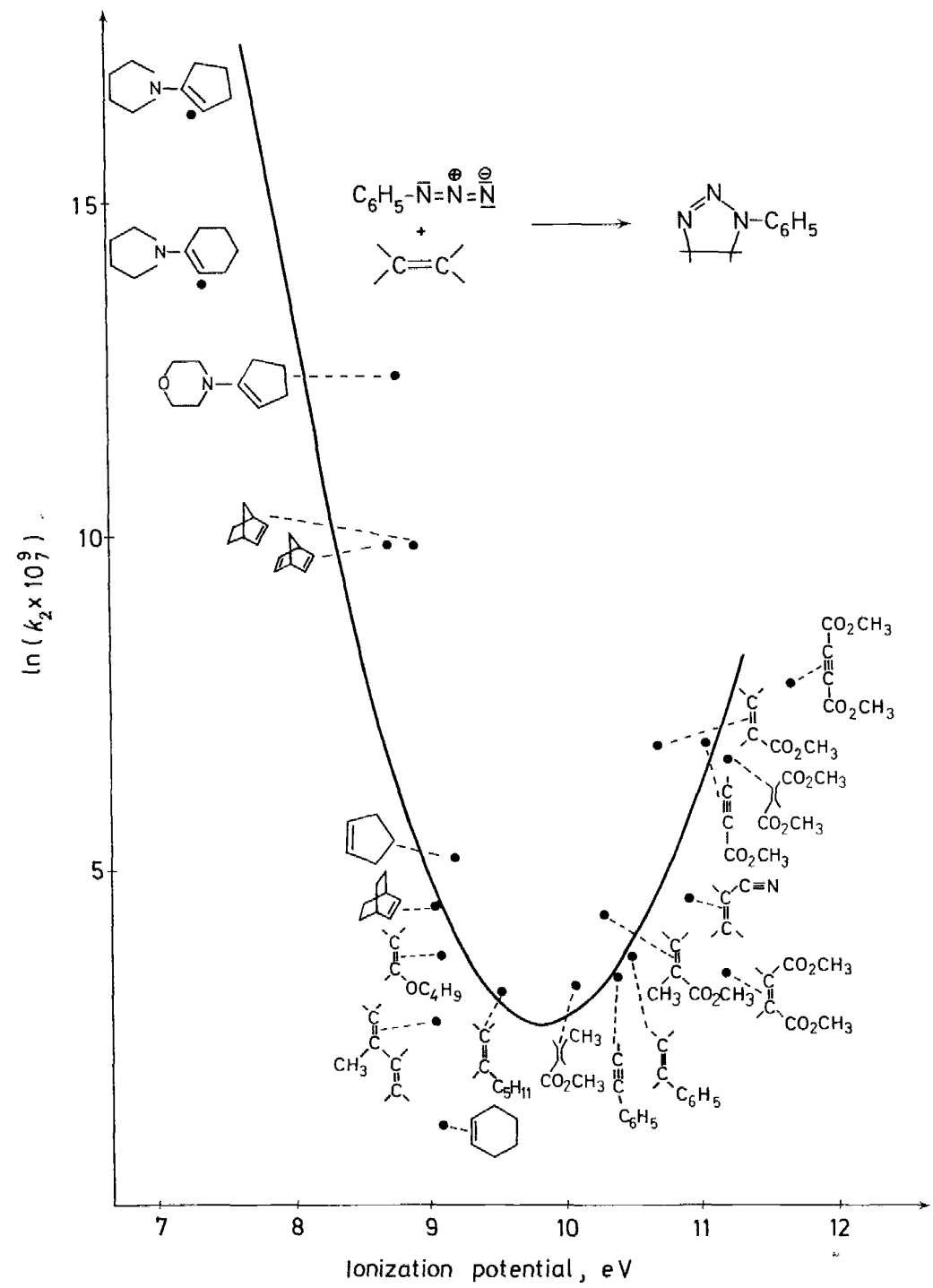

Figure 26. Correlation of HOMO energies with $\ln k_{2}$ values for cycloadditions of phenyl azide

The restrictions imposed by the neglect of the numerator of the expression have to be discussed in more detail. The numerator was treated as a constant. That this cannot be true is evident. The MOs of a molecule are delocalized and it is only to a certain extent that one may speak of localization in these unsaturated molecules. According to MINDO calculations for substituted olefins the $\mathrm{C}=\mathrm{C}$ double bond comprises on the average 60 to 80 per cent of the HOMO. Even though the largest contributions come from the carbon atoms directly involved in the cycloaddition process, these contributions 
vary with the nature of the substituent. This again will impair the quality of the correlation. That the structure of the HOMOs and LUMOs contains valuable information has been shown recently ${ }^{41-44}$. Houk and Bastide have used this extension of the reactivity model to rationalize regiospecificity in 1,3-dipolar cycloadditions which has been a vexing problem.

A final point may be discussed. Can the gap between this new kind of reactivity treatment and the old model of charge separation in the transition state be bridged? Figure 27 reproduces the frontier orbital arrangement for the normal Diels-Alder addition. Hitherto only the energetics of the formation of the new orbitals $\psi_{1}-\psi_{4}$ were discussed. However, one can qualitatively elaborate the structure of these new MOs. The weight of the coefficients of the linear combination of the isolated molecular orbitals is a function of the orbital separation. Each of the new MOs $\psi_{1}-\psi_{4}$ is a linear combination of the interacting MOs of dienophile and diene. $a$ and $b$ symbolize the weight with which the two MOs, capital $\Phi$ and small $\varphi$, contribute to $\psi$. It is obvious that in our example for $\psi_{1} a$ is much greater than $b$ and for $\psi_{2} b$ is greater than $a$. This combination process indicates that $\psi_{1}$ obtains a larger portion from the olefin than from the diene. $\psi_{2}$ on the other hand consists of contributions of $\varphi_{2}$ and $\Phi_{\mathrm{A}}$ which are similar. The consequence is a net flow of electronic charge from one reactant to the other, i.e. a charge separation as was assumed in the classic treatment. Thus, the old and new explanation have a lot in common. An example for a reaction of this type is given in the lower part of Figure 27.

In conclusion I summarize the advantages and disadvantages of the simple MO perturbation treatment. First the benefits: A plethora of data on cycloaddition reactions can be explained in a unifying model. It allows us to recognize the most important contributions to the reactivity. The qualitative nature is an advantage of this model, because it allows predictions to be made without recourse to calculations. However, the semiquantitative nature also imposes restrictions. Molecules are more than HOMOs and LUMOs. Thus one should not try to overdraw the model. A molecule has

MOs of transition state as LMCOS of ground state MOs

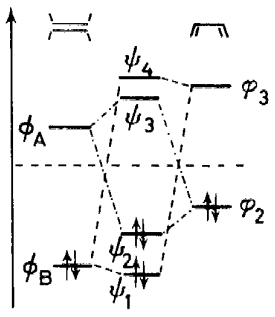

$$
\begin{gathered}
\quad \psi=a \phi+b \varphi \\
\psi_{1}: a \gg b \quad \phi_{B} \text { dominates in } \psi_{1} \\
\psi_{2}: b>a \quad \varphi_{2} \text { contributes more to } \psi_{2} \text { than } \phi_{A} \\
\text { but less than } \phi_{B} \text { in } \psi_{1}
\end{gathered}
$$

Consequence: charge separation

Example:
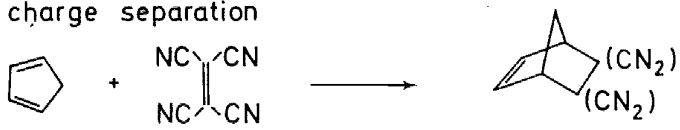

Figure 27. Charge separations in the transition state of concerted cycloadditions 


\section{REINER SUSTMANN}

spatial dimensions. During the interaction with a second molecule this may become an important property. Furthermore, most molecules do not have uniform charge distributions, i.e. have polarity, which may cause charge interactions. It will be hard to reach a satisfactory quantitative description of the interplay of these forces. This certainly cannot be done in a one-electron treatment of the Hückel type. The replacement of the $\pi$-electron approximation by valence electron theories creates even more difficulties. Here it becomes necessary to calculate or assume transition state geometries. The elegance of the simple theory then vanishes.

\section{REFERENCES}

1 R. Huisgen, R. Grashey and J. Sauer, in S. Patai, The Chemistry of Alkenes, p 739. Interscience: London (1964).

2 R. Huisgen, Angew. Chem. 80, 329 (1968).

3 W. C. Herndon, Chem. Reviews, 72, 157 (1972).

4 R. B. Woodward and R. Hoffmann, Angew. Chem. 81, 797 (1969).

5 M. J. S. Dewar, Tetrahedron Suppl. 8, 75 (1966); Angew. Chem. 83, 859 (1971).

${ }^{6}$ R. Huisgen and G. Steiner, J. Amer. Chem. Soc. 95, 5054, 5055, 5056 (1972); Tetrahedron Letters 3763 (1973);

R. Huisgen, R. Schug and G. Steiner, Angew. Chem. 86, 47 (1974).

7 J. S. Swenton and P. D. Bartlett, J. Amer. Chem. Soc. 90, 2056 (1968);

P. D. Bartlett, Science, 159, 833 (1968); Quart. Reviews 24, 473 (1970).

8 R. Huisgen, G. Szeimies and L. Moebius, Chem. Ber. 100, 2494 (1967).

9 R. Sustmann, Tetrahedron Letters, 2717 (1971).

10 R. Sustmann, Tetrahedron Letters, 2721 (1971).

11 A. Wassermann. Diels-Alder Reactions, Elsevier : New York (1965); J. Sauer, Angew. Chem. 78, 233 (1966); 79, 76 (1967).

12 R. Huisgen, Angew. Chem. 75, 604 (1963); 75, 742 (1963).

13 K. Fukui, Fortschr. Chem. Forsch. 15, 1 (1970).

${ }^{14}$ E. Heilbronner and H. Bock, Das HMO-Modell und seine Anwendung, Verlag Chemie: Weinheim/Bergstrasse (1968).

15 M. J. S. Dewar, The Molecular Orbital Theory of Organic Chemistry. McGraw-Hill : New York (1969).

16 J. Sauer, H. Wiest and A. Mielert, Chem. Ber. 97, 3183 (1964).

17 O. Eisenstein and N. T. Anh, Tetrahedron Letters, 1191 (1971).

18 W. E. Bachmann and N. C. Deno, J. Amer. Chem. Soc. 71, 3062 (1949).

19 J. Sauer and D. Lang, Angew. Chem. 76, 603 (1964).

20 A. I. Konovalov and B. N. Solomonov, Dokl. Akad. Nauk SSSR, Ser. Khim. 211, 1115 (1973).

21 Ch. Rücker, Dissertation, Universität München (1969).

22 G. Briegleb, Angew. Chem. 76, 326 (1964).

23 A. Eckell, R. Huisgen, R. Sustmann, G. Wallbillich, D. Grashey and E. Spindler, Chem. Ber. 100, 2192 (1967).

24 R. Eidenschink and Th. Kauffmann, Angew. Chem. 84, 292 (1972).

25 G. Boche and D. Martens, Angew, Chem. 84, 768 (1972).

26 R. Huisgen, H. Stangl, H. J. Sturm and H. Wagenhofer, Angew. Chem. 74, 31 (1962).

27 K. Bast, M. Christl, R. Huisgen and W. Mack, Chem. Ber. 106, 3312 (1973).

${ }^{28} \mathrm{Ch}$. Grundmann and P. Grünanger, The Nitrile Oxides. Springer: Berlin (1971).

29 R. W. Murray, Acc. Chem. Res. 1, 313 (1968).

30 P. R. Story, J. A. Alford, W. C. Ray and J. R. Burgess, J. Amer. Chem. Soc. 93, 3041 (1971).

31 T. Vrbaski and R. J. Cvetanović, Canad. J. Chem. 38, 1053 (1960).

32 R. Sustmann, Tetrahedron Letters, 963 (1974).

33 P. Beltrame, P. Sartirana and C. Vintani, J. Chem. Soc, B, 814 (1971).

${ }^{34}$ H. J. Schäfer, private communication.

${ }_{35}$ R. Sustmann and H. Trill, Angew. Chem. 84, 887 (1972).

36 D. W. Turner, C. Baker, A. D. Baker and C. R. Brundle, Molecular Photoelectron Spectroscopy. Wiley-Interscience: New York (1970). 


\section{ORBITAL ENERGY CONTROL OF CYCLOADDITION REACTIVITY}

37 P. Bischof, J, A. Hashmall, E. Heilbronner and V. Hornung, Helv. Chim. Acta, 52, 1745 (1969).

${ }^{38}$ R. Sustmann and R. Schubert, Tetrahedron Letters, 2739 (1972).

39 R. Sustmann and H. Trill, Tetrahedron Letters, 4271 (1972).

40 R. Sustmann and R. Schubert, Angew. Chem. 84, 888 (1972).

41 K. N. Houk, J. Sims, R. E. Duke Jr, R. W. Strozier and J. K. George, J. Amer. Chem. Soc. 95, 7287 (1973);

K. N. Houk, J. Sims, C. R. Watts and L. J. Luskus, J. Amer. Chem. Soc. 95, 7301 (1973).

42 J. Feuer, W. C. Herndon and L. H. Hall, Tetrahedron, 24, 2575 (1968).

43 O. Eisenstein, J. M. Lefour and N. T. Anh, Chem. Commun. 969 (1971).

44 J. Bastide, N. El Ghandour and O. Henri-Rousseau, Tetrahedron Letters, 4225 (1972);

J. Bastide, N. El Ghandour and O. Henri-Rousseau, Bull. Soc. Chim. France, 2290 (1973);

J. Bastide and O. Henri-Rousseau, Bull. Soc. Chim. France, 2294 (1973). 